\title{
El surrealismo de Octavio Paz: La hija de Rappaccini
}

\author{
María Elena IsIBASI PouCHIN \\ Universidad Nacional Autónoma de México
}

La relación de Octavio Paz con el surrealismo no es del todo convencional, ya que no cayó bajo el encanto bretoniano sino después de que el movimiento que éste lideraba ya había pasado de "moda". Sin embargo, se debe entender, primero y antes que todo, que el surrealismo no fue, ni para Breton, ni para Paz, una moda. Para ellos era una actitud del espíritu humano. Representaba —y según Paz siempre representará- la única posibilidad de resistencia frente a un mundo deshumanizado. Se trataba de subvertir una realidad que la sociedad se había empeñado en presentar como única y que ponía en tela de juicio a la misma libertad del hombre. El surrealismo afirmaba la necesidad de que la liberación del hombre fuera total — liberación de la razón y de las normas-; con ella se podrían reunir el pensamiento y la acción.

La interpretación que hace Octavio Paz del surrealismo francés sin duda se evidencia en su única obra de teatro. En ella no hay una exposición lógica de sus ideas -ideas que desarrolla extraordinariamente en El arco y la lira, Las peras del olmo y Los hijos del limo - éstas son representadas en una escenificación que recuerda tanto el teatro clásico como el teatro $n \bar{o}$ japonés y que crea un mundo de ensueño en donde todo es posible porque no es real. El poeta mexicano retoma un cuento de Nathaniel Hawthorne y lo reinventa. La historia es la misma, la intención es otra.

La hija de Rappaccini es representada por primera vez el 31 de julio de 1956 en el Teatro del Caballito. ${ }^{1}$ Es una de las cuatro obras que formaron parte del segundo programa "Poesía en Voz Alta" de la UNAM — las otras fueron Le salon de l'automobile de Ionesco, Oswald et Zénaïde ou Les Apartés de Tardieu y Le canari de Neveux, todas traducidas por Octavio Paz para este programa universitario. Dirigida por Héctor Mendoza, con escenografía y vestuario de Leonora Carrington, musicalizada

\footnotetext{
${ }^{1}$ Antonio Magaña Esquivel, compilador de Teatro mexicano del siglo XX (1970), indica que La hija de Rappaccini fue escrita en 1953 (cit. por Blasi 1979: 525). Sin embargo, Roni Unger, en su exhaustivo trabajo sobre el papel de "Poesía en Voz Alta" en el teatro mexicano, afirma que la obra de Paz fue escrita a partir de la propuesta de hacer de esta compañía una de teatro, en 1956: "Someone proposed that the company write its own plays, as the comercial and experimental groups of the 1920's and 1930's and the more recent amateur groups had done. This, Paz insists (and Carrington, Mendoza, and Ibáñez concur), elicited his announcement to do just that: to write a play for Poesía en Voz Alta. Il was to be La hija de Rappaccini [...] Paz's first and only play" (1981: 14).
} 
por Joaquín Gutiérrez Heras e interpretada, en el papel del Doctor Rappaccini, por Juan José Arreola, esta obra poco estudiada y muchas veces menospreciada, ${ }^{2}$ sintetiza en unas cuantas páginas el pensamiento de Paz: su lado surrealista, su búsqueda por el origen, la analogía que establece entre la creación poética y el acto erótico — ambos relacionados con los movimientos cósmicos- y su concepto de poesía universal. Es publicada el mismo año de su representación en la Revista Mexicana de Literatura (1956), y es incluida en Teatro mexicano del siglo XX (1970). Además forma parte del libro de Paz que reúne sus Poemas de 1935 a 1975, y de su Obra poética (1935-1988), ambas ediciones a cargo de Seix Barral (1990). ${ }^{3}$ Finalmente, el autor decide integrar La hija de Rappaccini en su Obra completa en el volumen XI -Obra poética I- a cargo del Fondo de Cultura Económica. Una edición independiente sale en 1990 en la editorial Era. ${ }^{4}$

Resulta curioso a primera vista que Paz haya decidido situar su única obra de teatro en el primer volumen de sus Obras completas dedicado a la poesía. De hecho, ya desde Poemas (1935-1975) —y Obra poética (1935-1988) — Paz dispone La hija de Rappaccini después de Libertad bajo palabra. Esto podría explicar la razón por la cual esta obra no parece una de teatro —o lo que se considera como teatro moderno. ${ }^{5}$ Además, el mismo autor, en el prólogo al volumen que incluye esta pieza, dice que "La hija de Rappaccini es un poema dramático y viene precisamente de un cuento" (1997: 19). No es mi intención aquí debatir sobre el género de esta obra, sólo me limitaré a decir que con ella Paz nos recuerda que en un principio el teatro era poesía y que lo que se pone en escena no es otra cosa que una tragedia. Así, se puede decir que, a pesar de que Paz se inspira en un cuento de Hawthorne, en realidad la intención, y por ende el resultado, de esta adaptación es muy diferente a la del escritor estadounidense.

\footnotetext{
${ }^{2}$ Raúl Chavarri dice que no es sino quince años después de la representación de la obra, es decir, en 1971, que Emilio Carballido "censura el carácter anodino con que interpretó la crítica contemporánea la obra" (1979: 505). Este último critica a los que no han visto más que una adaptación —en el sentido negativo de la palabra - del cuento de Hawthorne en la obra de Paz: "En cuanto al término adaptar: posee un matiz preciso, que sugiere inmediatamente los trajes viejos adaptados a la medida del hermanito menor por una sastre remendón. Adaptar, esto es, modificar algo cortándole aquí, aumentándole allá, y así con un producto original se logra uno derivado y subordinado. Un cuento sufre ligeras modificaciones y se vuelve un drama. Para usar el ejemplo más ilustre: ciertas novelas italianas son cuidadosamente parchadas y remendadas por un autor inglés con buen oficio: el subproducto nos resulta Romeo y Julieta, Otelo..." (cit. por Dauster 1978: 157). No sobra decir que incluso hoy, a cincuenta años de su primera representación, La hija de Rappaccini de Octavio Paz no ha recibido la atención que merece puesto que el número de estudios y trabajos sobre esta obra son sin duda alguna poco numerosos (cf. Bibliografía critica de Octavio Paz de Hugo Verani).

${ }^{3}$ Obra poética (1935-1988) recoge Poemas (1935-1975) y agrega Árbol adentro (1976-1988).

${ }^{4}$ Daniel Catán compone una ópera basada en La hija de Rappaccini de Octavio Paz. Esta ópera es representada en 1991. Sobre esto se puede leer a Daniel Catán (1991).

${ }^{5}$ En realidad, como lo indica Chavarri, "se advierte en Octavio Paz el afán de renovar la función poética del drama, sacar a la poesía de su soledad, de su clandestinidad, para recuperar acción y procurar la reconciliación de los términos poesía-teatro" (1979: 506).
} 
Me parece pues importante recordar, en este punto, las ideas de Paz sobre la imitación y la creación. En su ensayo Traducción: Literatura y Literalidad, el escritor mexicano explica que para él "en cada periodo los poetas europeos — ahora también los del continente americano, en sus dos mitades- escriben el mismo poema en lenguas diferentes. Cada una de estas versiones es, asimismo, un poema original y distinto" y sigue: "Cierto, la sincronía no es perfecta, pero basta alejarse un poco para advertir que oímos un concierto en el que los músicos, con diferentes instrumentos, sin obedecer a ningún director de orquesta ni seguir partitura alguna, componen una obra colectiva en la que improvisación es inseparable de la traducción y la invención de la imitación" (1971: 25).

Paz no vuelve a decir explícitamente lo que opina sobre esto pero lo expone en su obra de teatro. En efecto, el poeta mexicano reproduce un cuento de Hawthorne, el cual, a su vez, retoma la historia de una "vieja conseja norteamericana de origen italiano" (Chavarri, 1979: 506). Este juego de reproducciones se da también a nivel ficcional: Hawthorne comienza su cuento introduciendo un autor ficticio $-\mathrm{M}$. de l'Aubépine - especificando que el cuento que sigue a esa presentación en realidad es una traducción del texto original en francés. Cabe mencionar que "aubépine" es la exacta traducción al francés de "hawthorn", y se refiere al espino. El autor real se identifica entonces de alguna manera con el ficticio y el significado de su nombre viene muy a caso con la historia del joven estudiante de leyes y su encuentro con Beatriz puesto que el espino, como su nombre lo indica, es un arbusto lleno de espinas pero también de flores blancas olorosas. Beatriz es una mujer "espinosa", peligrosa porque su solo contacto es mortal pero es "una de las criaturas más bellas que han visto estos viejos ojos" (Paz, 1990: 21).

Dentro del cuento del supuesto Aubépine, uno de los personajes, el Doctor Baglioni, introduce la historia análoga a la de Giovanni Guasconti, la de la hermosa mujer dada en obsequio por un príncipe indio a Alejandro Magno. En este juego de reproducciones, la obra de Paz no sería sino una reproducción de una reproducción, de una reproducción... como en una serie de cajas chinas. Y sin embargo, estas cajas no son idénticas, todas son diferentes, originales. Octavio Paz ejemplifica esta idea de originalidad a partir de la "imitación" tomando como modelo la poesía de Jules Laforgue y su "reproducción" por parte de Leopoldo Lugones y de Ramón López Velarde. Sobre el primero dice que "publica Lunario sentimental: a despecho de ser una imitación de Laforgue, este libro fue uno de los más originales de su tiempo y todavía puede leerse con asombro y delicia", y concluye sobre los dos poetas hispanoamericanos: "Dos poetas escriben, casi en los mismos años, en lenguas distintas y sin que ninguno de los dos sospeche siquiera la existencia del otro, dos versiones diferentes e igualmente originales de unos poemas que unos años antes había escrito un tercer poeta en otra lengua" (1971: 26-27). La idea entonces de que todos los poetas en realidad escriben el mismo poema en lenguas diferentes, es puesta en escena en la pieza de Paz puesto que en ésta se presupone el conocimiento del cuento de Hawthorne y de la compleja red que construye: el texto indio (sánscrito clásico), el texto francés, su traducción al 
inglés y su adaptación al español dan fe de la concepción que tiene Paz de la universalidad de la poesía.

Paz introduce algunos cambios en la historia, aquí mencionaré los más importantes. Por una parte, evidentemente el cambio más fehaciente es que en su caso se trata de una puesta en escena, lo cual condiciona la expresión de la historia. Por otra parte, se obvia el relato de la "fábula india" y finalmente se introduce un personaje inexistente en el cuento de Hawthorne: el Mensajero.

La hija de Rappaccini se compone de un prólogo, nueve escenas y un epílogo. El tema principal es el amor y la elección que implica ese amor: vida — supervivencia en un mundo temporal y social—o muerte —reclusión en un espacio cerrado, "mítico". El prólogo y el epílogo están a cargo del Mensajero así como las escenas cuarta y séptima. Tres de los personajes tienen los mismos nombres que en el cuento de Hawthorne aunque traducidos del italiano al español: Juan, Beatriz e Isabel; y dos guardan sus nombres —o mejor dicho apellidos — : los doctores Rappaccini y Baglioni. Ya he dicho al principio de este trabajo que en la obra de Paz se crea un mundo de ensueño y de alguna manera alegórico - no tanto como en el texto del escritor americano, el cual expresa él mismo su amor por la alegoría ("[His writings] might have won him greater reputation but for an inveterate love of allegory, which is apt to invest his plots and characters with the aspect of scenery and people in the clouds, and to steal away the human warmth out of his conceptions") (Hawthorne, 1982). Esta impresión de irrealidad la da desde el principio el personaje del Mensajero. Frank Dauster, en su ensayo " $L a$ hija de Rappaccini: dos visiones de la fantasía", piensa que "esta figura le da a la obra un aire de fantasía, de irrealidad, desde el comienzo, aire fortalecido por la presentación marcadamente antirrealista" (1978: 159). Por supuesto, el crítico se refiere al prólogo en el que el Mensajero se define en los siguientes términos:

Mi nombre no importa. Ni mi origen. En realidad no tengo nombre, ni sexo, ni edad, ni tierra. Hombre o mujer; niño o viejo; ayer o mañana; norte o sur; los dos géneros, los tres tiempos, las cuatro edades y los cuatro puntos cardinales convergen en mí y en mí se disuelven. Mi alma es transparente: si os asomáis a ella, os hundiréis en una claridad fría y vertiginosa; y en su fondo no encontraréis nada que sea mío. Nada, excepto la imagen de vuestro deseo, que hasta entonces ignorabais. Soy el lugar de encuentro, en mí desembocan todos los caminos (1990: 15-16). ${ }^{6}$

\footnotetext{
${ }^{6}$ En todas las ediciones, este párrafo termina “...un nudo de llamas"; sin embargo, tanto es la $R e$ vista Mexicana de Literatura (1956) como en Teatro mexicano del siglo XX (1970), éste termina: "El encuentro libremente aceptado, fatalmente elegido". Esta frase justificaría el hecho de afirmar, además de que esta intervención da la impresión de un mundo de ensueño, que tiene una función premonitoria, puesto que anuncia el fracaso de lo que se va a contar con la sola mención de la fatalidad. Octavio Paz la elimina en las siguientes ediciones que incluyen su obra probablemente porque esta oración aclara demasiado, adelanta y hace casi obvio lo que el espectador debe esperar.
} 
El Mensajero es un personaje ambiguo; en él se condensan la Nada y la culminación de todo. No es hombre o mujer, no es joven ni anciano, existe y no existe, todo en él se construye y se disuelve. Su papel no es gratuito; el lirismo de la obra es establecido gracias a él y a sus intervenciones en momentos clave para el desarrollo de la historia. Él "encarna", según Chavarri, "la figura de un narrador, que en el teatro de la ciudad antigua es una entidad colectiva y toma la forma de coro, se enlaza con la serie de figuras que en la tragedia griega se hacen portavoces de la expresión del destino" (1979: 509). Concuerdo con ambas afirmaciones aunque creo que es necesario ahondar un poco en ellas. El Mensajero efectivamente narra, pero no narra la historia, él pertenece al mundo de los sueños, de la fantasía; es testigo de las acciones que llevan a cabo los personajes principales, los amantes - Juan y Beatriz - en su estado onírico. En la escena cuarta, por ejemplo, este personaje pone en palabras el sueño de Juan mientras éste reproduce con gestos lo que va contando el Mensajero ("Durante esta escena, Juan mima las palabras del Mensajero") (1990: 30). En la escena séptima, aunque los enamorados no están durmiendo, la descripción que hace de las acciones de los personajes no es una que pueda adjudicarse al estado de vigilia. La comparación - no explícita - con el movimiento del sol y de los planetas los pone en un nivel distinto al de la realidad, un nivel "cósmico" ("Él da vueltas alrededor de ella, que gira sobre sí misma [...] Pero nunca se tocan, condenados a girar interminablemente, movidos por dos poderes enemigos, que los acercan y separan”) (1990: 42-43). También en esta escena los personajes reproducen físicamente lo dicho por el Mensajero. Sobre esto Dauster piensa que Paz, al recurrir a la mímica, actualiza "una de las formas más arcaicas del teatro, el mimo con comentario, representación teatral del sueño como regreso a la capa más arcaica, más fundamental, más pura quizá, de nuestra existencia”, y más adelante confirma que con esto "se repite, pues, la función anterior del Mensajero: establecer el clima de fantasía, tal que la superficie, la aparente realidad, se haga transparente, y vemos así lo verdadero real: la vida de ensueño, de dos jóvenes al borde del instante puestos a escoger su realidad" (1978: 162).

En cuanto a que la figura del Mensajero se relaciona "con la serie de figuras que en la tragedia griega se hacen portavoces de la expresión del destino", esto se puede confirmar gracias a la importancia que se le da a las cartas del Tarot. Prólogo y epílogo hablan de ellas. El Tarot, como es bien sabido, tiene como función primordial la premonición. Esto también le da una dimensión mágica a la obra de Octavio Paz. El Mensajero es un "personaje hermafrodita vestido como las figuras del Tarot, pero sin copiar a ninguna en particular" (1990: 15) —además de funcionar como "narrador", testigo de los estados oníricos de los personajes, el Mensajero es una figura mágica, premonitoria, que pertenece a otro nivel de la realidad. En su primera aparición saca diferentes cartas del Tarot: la Reina, el Rey “de este mundo” y “justiciero y virtuoso”, el Ermitaño, el Juglar y Los Amantes. Aunque Dauster y Chavarri afirmen que no hay relación entre las cartas y los personajes de la obra, tiendo a pensar lo contrario. Si bien es cierto que no es fácil identificar al correspondiente de cada figura del Tarot, tampoco se puede decir que no es posible establecer una relación entre los naipes y los diferentes personajes. 


\section{EL SURREALISMO DE OCTAVIO PAZ: LA HIJA DE RAPPACCINI}

Si se considera a esta obra como un "drama alegórico-simbólico", en términos de Irma González Pelayo, entonces estaremos de acuerdo con ella en que La hija de Rappaccini "remite al periodo surrealista de Paz" (1991: 123). Y entonces aquí el sueño y la alegoría se condensarían en el personaje del Mensajero. Las imágenes del sueño, y de estados análogos a éste - como la locura o el sueño diurno, por ejemplo- a decir de los surrealistas, desafían a la realidad al punto de provocar una ruptura de la visión convencional que de ésta se tiene. ${ }^{7}$ El mismo Paz define al surrealismo como una "desesperada tentativa por encontrar la vía de salida. No, ciertamente, en busca de la salvación, sino de la verdadera vida" (1994: 203). El poeta mexicano piensa que los poderes que pueden llevarnos a esta verdadera vida se encuentran en nosotros mismos y pueden ser llamados imaginación y deseo (1994: 204). Animado por su propio deseo, el hombre busca fundirse con la imagen de su sueño y así romper con la "realidad" para encontrar la verdadera vida. Aquí cabe hacer una observación. El Mensajero dice en el Prólogo que no encontraremos nada en su alma "excepto la imagen de [nuestro] deseo, que hasta entonces [ignorábamos]" (1990: 15-16). Si el Mensajero no tiene por alma más que el reflejo del deseo, entonces ¿qué representa en la obra de Paz?

La imaginación y el deseo pertenecen a la edad infantil, ésa en la que, como dice Breton, "la ausencia de toda norma conocida ofrece al hombre la perspectiva de múltiples vidas vividas al mismo tiempo" (1985: 17); ésa en la que el hombre permanece inocente, esa edad en la que no ha perdido la capacidad de asombro frente al mundo. El ser humano se ve obligado a mirar hacia atrás, no hacia el pasado sino hacia el origen, hacia el interior para poderse encontrar, para que emerja ese "otro" que es. En La hija de Rappaccini este regreso al origen se puede ver en la escena cuarta cuando Juan está soñando:

¡Ciérralos, retrocede, vuelve a lo oscuro, más allá de tu infancia, hacia atrás, hacia el origen! ¡Olas de tiempos contra tu alma! Rema contra ellas, rema hacia atrás, remonta la corriente, cierra los ojos, desciende hasta la semilla. Alguien ha cerrado tus párpados. La prisión transparente se derrumba, los muros de cristal yacen a tus pies, convertidos en un remanso de agua pacífica. Bebe sin miedo, duerme, navega, déjate conducir por el río de ojos cerrados. La mañana nace de tu costado (1990: 30).

\footnotetext{
${ }^{7}$ André Breton, en el "Manifiesto del surrealismo" de 1924, muestra que la locura es causada, de alguna manera, por la imaginación, puesto que ésta invita a romper las reglas de cierto orden preestablecido socialmente: "Estoy plenamente dispuesto a reconocer que los locos son, en cierta medida, víctimas de su imaginación, en el sentido que ésta les induce a quebrantar ciertas reglas, reglas cuya transgresión define la calidad de loco" (1985: 19). Paz no sigue al pie de la letra las recomendaciones hechas en los diferentes manifiestos del surrealismo escritos por André Breton. De hecho, como dice Jason Wilson, "Paz had stressed not the techniques like automatic writing or games or chance association or dream telling or trouvailles but surrealism's 'intransigent affirmation of certain values' [...] He lifted surrealism out of its time and historical / social contexts to make it an attitude of mind based on a subversive values of erotic love, the Other (woman), and inspiration" (1986: 35).
} 
La reconciliación entre el "yo" histórico, temporal, y el "yo" atemporal, original, se da en ese espacio que representa el Mensajero:

¡Espacio, puro espacio, nulo y vacío! Estoy aquí, pero también estoy allá; todo es aquí, todo es allá. Estoy en cualquier punto eléctrico del espacio y en cualquier fragmento imantado del tiempo: ayer es hoy; mañana, hoy; todo lo que fue, todo lo que será, está siendo ahora mismo, aquí en la tierra o allá en la estrella. El encuentro: dos miradas que se cruzan hasta no ser sino un punto incandescente, dos voluntades que se enlazan y forman un nudo de llamas (1990: 16). ${ }^{8}$

El "encuentro" como dos miradas, dos voluntades, alude a la experiencia amorosa de la que Juan y Beatriz serán protagonistas. Como se ha dicho, el hombre busca fundirse con la imagen de su propio sueño para encontrar la verdadera vida; en realidad, al fundirse con esa imagen se fusiona con el "otro" que es; ese otro también es representado por la Mujer, y también se puede llegar a la verdadera vida por medio de la experiencia amorosa.

Esta experiencia se hace evidente en La hija de Rappaccini en la escena sexta. Se establece una analogía entre lo erótico, la naturaleza y el universo:

JUAN: Rodearte como el río ciñe a una isla, respirarte, beber la luz que bebe tu boca [...] Recorrer interminablemente tu cuerpo, dormir en tus pechos, amanecer en tu garganta, ascender el canal de tu espalda, perderme en tu nuca, descender hasta tu vientre. Perderme en ti, para encontrarme a mí mismo, en la otra orilla, esperándome. [...]

BEATRIZ: Girar incansablemente a tu alrededor, planeta yo y tú sol.

JUAN: Frente a frente siempre como dos árboles (1990: 38-39).

La experiencia erótica hace descubrir el universo. En la obra de Paz, naturaleza, universo y erotismo están en el mismo nivel. El autor equipara el acto amoroso con los movimientos del universo. Explica esta idea y la profundiza en Los hijos del limo, en donde dice que "la creencia en la analogía universal está teñida de erotismo: los cuerpos y las almas se unen y separan regidos por las mismas leyes de atracción y repulsión que gobiernan las conjunciones y disyunciones de los astros y de las sustancias materiales. Un erotismo astrológico y un erotismo alquímico; asimismo, un erotismo subversivo" (1989: 103).

\footnotetext{
${ }^{8}$ En Los hijos del limo, Octavio Paz concuerda con Dante al pensar en el "nudo" como en la unión de sustancia y accidente, dice que "ese nudo es la forma universal que encierra a todas las formas. El nudo es el jeroglífico del amor divino" (1989: 112-113). La alusión a Dante no es del todo coincidental; en La hija de Rappaccini, el nombre de la protagonista, Beatriz, recuerda sin duda a la de $L a$ divina comedia, en donde el amor se pone a prueba. De hecho, Lois Parkinson Zamora, en su ensayo “A garden inclosed: 'Fuentes' Aura, Hawthorne's and Paz's 'Rappaccini's Daughter', and Uyeda's Ugetsu Monogatari", dice sobre Giovanni (Hawthorne) que como Dante "to whom he is compared, is accompanied into an infernal region by Beatrice, but through her he has the opportunity as well to behold undreamed of wonders" (1984: 322).
} 
Este movimiento de atracción y repulsión se puede ver también en la creación poética. La creencia en una analogía universal lleva a pensar, desde Baudelaire, que "el poema es el doble del universo: una escritura secreta, un espacio cubierto de jeroglíficos. Escribir un poema es descifrar el universo sólo para cifrarlo de nuevo", aunque la pluralidad de textos denuncia la inexistencia de un texto original que sea reflejo del universo en su totalidad, lo cual hace que al mismo tiempo que se acepta la analogía universal se la rechace.

Así, poesía, universo y erotismo son análogos por sus movimientos. El lenguaje adquiere en La hija de Rappaccini otra dimensión. La obra de teatro es el resultado de la experiencia poética, experiencia equiparable a la erótica — encarnada aquí por Juan y Beatriz - y a la cósmica (que se relaciona con la naturaleza) — representada aquí con la comparación entre Beatriz y el árbol que domina el jardín de Rappaccini. Paz reúne así las tres experiencias y nos las ofrece en una escenificación que evidencia su analogía. Si sólo se considera el acto erótico — que finalmente nunca culmina - se verá que así como le devuelve la vida a Juan, por el hecho de estar enamorado, también lo amenaza de muerte por su cercanía al veneno que supura Beatriz: "Al verla, entre tanta planta desconocida, la reconocí, familiar como una flor y, no obstante, remota. La vida brotando entre las rocas de un desierto, con la misma sencillez con que la primavera nos sorprende cada año. Todo mi ser empezó a cubrirse de hojas verdes. Mi cabeza, en lugar de ser esta triste máquina que produce confusos pensamientos, se convirtió en un lago" (1990: 37).

Juan, que pertenece al mundo exterior, parece estar muerto, es una "triste máquina" que cobra vida al entrar en contacto con el objeto deseado. Pero al estar tan cerca de la vida que le otorga el amor también se acerca peligrosamente a la muerte ("Lo que tú llamas vida engendra la enfermedad, la locura y la muerte. Tu aliento mata", 1990: 50). El descubrimiento, en el desarrollo de la obra, de esta dualidad (vida / muerte) que provoca el amor, explica la última frase del Mensajero en el Prólogo: "El amor es elección: ¿la muerte o la vida?” (1990: 17). Por su lado, Beatriz, que vivía en el jardín de plantas venenosas, encuentra la muerte por el antídoto que el Doctor Baglioni da a Juan. Este líquido medicinal, supuestamente con propiedades curativas, que revierten el efecto del veneno, es el veneno para la protagonista; el amor la ha hecho elegir entre la vida y la muerte y ella ha elegido la muerte.

Erotismo y naturaleza son dadores de vida y de muerte. La naturaleza tiene propiedades curativas y propiedades venenosas y, así como en el amor, se debe escoger entre vivir y morir. El Doctor Rappaccini conoce bien la doble función de las plantas:

Venenos y antídotos: una y la misma cosa. Belladona, agua tofana, cicuta, beleño negro, heléboro. ¡Qué infinita riqueza de formas y qué variedad de efectos! El lactáreo venenoso, el bálano impúdico, la niebla, el ceñiglo, la hipócrita coralina, el pedo de lobo y el boleto de Satanás... Y a su lado, separados por una pulgada apenas en la escala de las formas, el licopodio y la pulmonaria, el musco oriental y el verdín doméstico, terror de las cocineras. Y no obstante, el principio es el 
mismo: basta un pequeño cambio, una leve alteración, y el veneno se transforma en elíxir de vida. Muerte y vida: ¡nombres, nombres! (1990: 23-24).

Vida y muerte son las dos rutas a las que se refería el Mensajero en el Prólogo. Se debe escoger entre ellas cuando el camino se bifurca al experimentar el amor o la naturaleza. Todo en la obra se resume en el aliento de Beatriz, primero, y de Juan, después. Todo pasa por la boca: por ella nace el amor entre los amantes —el contacto se hace por la palabra - y por ella muere - Beatriz muere por beber el antídoto que le da Juan. La palabra, el lenguaje, tiene entonces también el poder constructivo y destructivo, tanto como el amor o la naturaleza.

Veneno y antídoto son ambos el significado de la palabra griega pharmakos. Esta palabra era, según René Girard, la que designaba "el mal y el remedio, y, finalmente, toda sustancia capaz de ejercer una acción muy favorable o muy desfavorable, según los casos, las circunstancias, las dosis utilizadas" (1983: 103). Pero también era la palabra que se usaba para nombrar a aquellas personas, criadas y mantenidas por el estado de Atenas, que en caso de necesidad eran sacrificadas para mantener el orden social. La muerte de la víctima del sacrificio "purga efectivamente a la comunidad puesto que le devuelve la tranquilidad", ella "[drena] todas las impurezas y las [consagra] sobre su cabeza" y después se la "[expulsa o se la mata] en una ceremonia en la que [participa] todo el populacho" (1983: 103). Entonces, en el caso de la obra de Paz, y de Hawthorne antes que él, Beatriz encarna los dos sentidos de la palabra pharmakos: ella es veneno — para el cuerpo- y antídoto — por medio de su amor-, pero al mismo tiempo es la víctima sacrificial de la sociedad de Padua de la que forman parte Juan y el Doctor Baglioni. Ella es una víctima porque no tiene culpa de nada ("No tuve culpa. Nada vivo me rodeaba, no hice mal a nadie, excepto a mí misma", 1990: 51) y sin embargo representa una aberración por ser, en su esencia, contraria al resto del mundo (vive de la muerte). Paz lograr condensar una multitud de significados en este complejo personaje femenino. Beatriz es la naturaleza, la contraparte del "yo" que permite la unión y la experiencia amorosa, la representación de la vida y la muerte, la víctima sacrificial... ella es la dualidad, presente en todos los elementos, encarnada.

Aunque en Beatriz y en Juan se pueden ver la vida y la muerte, éstas también se hacen evidentes porque se hacen "físicamente palpables" en dos espacios creados por el autor, espacios visibles para el espectador: la muerte es el jardín de Rappaccini, ese jardín cerrado entre paredes; y la vida es lo que está fuera del jardín: la habitación de Juan, la calle, Padua. Mucho se ha comparado este jardín al del mito del paraíso, presente en muchas culturas, la más cercana a nosotros siendo la judeo-cristiana. La mayoría de los críticos han hecho ya el estudio de este tema (refiriéndose al cuento de Nathaniel Hawthorne), aquí sólo me limitaré a resumir lo ya dicho puesto que no es mi intención repetir lo que otros ya han indicado. ${ }^{9}$

\footnotetext{
${ }^{9}$ Remito al ensayo ya citado de Lois Parkinson Zamora.
} 
El dios judeo-cristiano crea el edén que no es más que un jardín en el centro del cual se encuentra un árbol — de la sabiduría; del Bien y del Mal. También crea a Eva para que viva en este jardín - convirtiéndose así en su padre. Ella desobedece a su creador comiendo el fruto prohibido del árbol y es expulsada del jardín, entrando así en el mundo temporal y mortal. En La hija de Rappaccini se reproduce el mito: el Doctor Rappaccini desempeña el papel de Dios al crear un jardín de plantas inexistentes con un árbol que domina el espacio, y una hija que en lugar de aliento de vida tiene aliento de muerte. Beatriz también desobedece a su padre al ingerir el antídoto que le da Juan y también es expulsada de alguna manera de su propio paraíso al morir. Sin embargo, en la historia que Paz reproduce hay una inversión de "responsabilidades". En el mito del edén, Eva es la que incita a Adán a comer la manzana y así a caer en el pecado que origina la muerte; en la historia de Hawthorne y de Paz, es Juan el que tienta a Beatriz para que tome el líquido que la hace morir. Se trata de una reivindicación de la mujer ("Te quise hacer más fuerte que la vida: ahora humillaré a la muerte") (1990: 54). Hawthorne la hace más explícita en su cuento: “'Miserable!' exclaimed Rappaccini. 'What mean you, foolish girl? Dost thou deem it misery to be endowed with marvellous gifts, against which no power nor strength could avail an enemy? Misery, to be able to quell the mightiest with a breath? Misery, to be as terrible as thou art beautiful? Wouldst thou, then, have preferred the condition of a weak woman, exposed to all evil, and capable of none?"” (1982: 1005).

Fuera de esta comparación que se puede hacer entre el jardín del edén y el jardín de Rappaccini, es posible establecer, como ya he dicho, un significado diferente al jardín. Éste es el espacio interior, encerrado, en el que se encuentra el mundo atemporal, mítico. El tiempo que rige a la realidad no tiene cabida en el universo que ha creado el Doctor Rappaccini. En él, el árbol, las plantas y su hija son inmortales — porque desde la perspectiva del exterior ya están muertos. En él, la vida es cíclica; sus componentes se regeneran una y otra vez: nacen, crecen, maduran y sueltan semillas que reinician el proceso sin que nada los limite ("Mi vida era crecer, respirar, madurar. ¡Ay, madurar!") (1990: 51). Este espacio representa el regreso al origen, en donde el universo y el ser son uno. En este espacio interior se encuentran el Doctor Rappaccini, su hija y Juan.

Como mencioné páginas atrás, los personajes pueden relacionarse de alguna manera con las cartas del Tarot que saca el Mensajero en su primera intervención. Estos naipes no los representan en su totalidad, es decir, en su complejidad; sin embargo, sí muestran una parte de su personalidad. Los personajes, como las personas en la vida real, no sólo muestran una cara; cambian según las circunstancias; en las cartas sólo se "expresa" una faceta, o varias como en el caso de Beatriz, a quien se puede relacionar con la Reina: "la pastora de los muertos en los valles subterráneos; la madre de las cosechas y los manantiales" (1990: 16). Aquí se puede ver la dualidad de Beatriz: es muerte y vida a la vez (las cosechas y los manantiales están vivos, la Reina les da vida puesto que es su madre). Beatriz es sin duda el personaje más complejo puesto que, además de representar la dualidad de la Reina, también se la puede identificar con la Amante, aunque no se sabe si es la figura "color del día" o "color de la noche" — esto es relativo 
porque, como se ha visto, puede ser día ya que gracias a ella Juan se siente más vivo, o noche puesto que en ella lleva la muerte. El Amante, el segundo de la misma carta, es Juan. Tampoco de él se puede afirmar si es día o noche puesto que le da vida a Beatriz por su amor y al mismo le da muerte con el antídoto. En el espacio exterior, Juan no es el Amante, es el Juglar de las cartas del Tarot ("el adolescente; dormía la cabeza reclinada sobre su propia infancia") (1990: 17); esto se hace evidente en la escena ya citada en que busca regresar al origen.

Los dos Amantes pertenecen al mundo del jardín, al del interior, al que es luminoso a pesar de ser el espacio de la muerte ("iQué luz dorada! [Acercándose al balcón] Y hay un jardín") (1990: 20) —en contraste con el mundo exterior que es oscuro ("Este cuarto es demasiado oscuro") (1990: 20). Las imágenes “oximorónicas" —luz / muerte, oscuridad / vida — están presentes en toda la obra; las ideas preconcebidas son así destruidas y el espectador queda desconcertado gracias a la puesta en escena. Los dos espacios - interior y exterior - no corresponden a lo que se esperaría; de esta manera se ponen en entredicho, desde el principio, el Bien y el Mal, ideas que hasta ese momento el espectador tenía "claras" en su mente. La oposición entre estos conceptos se diluye conforme va avanzando la representación hasta desaparecer e incluso invertirse.

A este espacio cerrado también pertenece el Doctor Rappaccini, un erudito (el "Ermitaño" de las cartas de Tarot, al cual se identifica con la sabiduría) que practica una ciencia experimental, no aceptada por el resto de la comunidad científica. Su papel se equipara más al de mago - al de creador, al de Dios, como se ha dicho. Él transgrede las reglas y eso lo hace ser temido, reprobado, y hasta cierto punto envidiado ("Hijo mío, la ciencia se hizo para él y no el hombre para la ciencia") (1990: 32) por el Doctor Baglioni — que representa a la ciencia académica conservadora. Así como Beatriz es portadora de muerte, así Rappaccini es creador de muerte y desde la perspectiva del mundo exterior, él es monstruoso por haber hecho de su hija un experimento más. Sin embargo, si se contrapone al mundo interior — el jardín — con el mundo exterior, se verá que la monstruosidad es invertida en el momento en el que Juan y Beatriz se enamoran. ¿Quién es peor? ¿Rappaccini por haber condenado a su hija a la soledad o Baglioni por "matarla" con su antídoto, en aras de demostrar su supremacía como científico? ¿No se vuelve la obra una competencia entre científicos? ¿No quiere Baglioni destruir lo que ha construido Rappaccini? Bien y Mal se confunden.

Los espacios interior y exterior, al principio bien separados, comienzan a contaminarse uno a otro. El primero en "invadir" es el espacio exterior puesto que Juan introduce un objeto ajeno al jardín ("JUAN [arrojándole el ramo]: ¡Son rosas acabadas de cortar! Si las huele, le dirán mi nombre!”) (1990: 27). Sin embargo, también el lugar que parece no haber sido tocado por la vida real, y que no parece haber interferido en ella, comienza a dejar rastros en el exterior ("Hablo seriamente: el aroma que tan sospechosamente inunda tu cuarto, ¡viene de allí, sube de ese jardín! Y sale de tu boca: tú lo exhalas cada vez que abres los labios") (1990: 45); y esto hace pensar en la existencia de un tercer espacio, uno intermedio que no pertenece al mundo de la muerte o al mundo de la vida, éste se ubica en el mundo de los sueños. El Mensajero es 
quien reina en este espacio - también pertenecen a él Juan (mientras duerme) y Beatriz (junto con Juan cuando miman las palabras del Mensajero en la escena séptima). El Mensajero no encarna - puesto que no se sitúa en ninguno de los espacios explícitos de la obra - ninguna figura de las cartas del Tarot, sin embargo, se lo puede relacionar con los naipes, puesto que las indicaciones escénicas que introducen el Prólogo lo describen como un "personaje hermafrodita vestido como las figuras del Tarot, pero sin copiar a ninguna en particular" (1990: 15). Él conoce todo lo que sucede en el jardín y en la habitación de Juan (el exterior) pero no interviene en el desarrollo de la acción. Su presencia es casi fantasmagórica. Cabe aclarar que si bien el Mensajero es quien reina en este espacio, Juan es el que permite su existencia. Él es el Amante y el Juglar de las cartas del Tarot; él pertenece al mundo interior y al mundo exterior. Él es el único de los personajes que transgrede los límites espaciales establecidos por la trama. Se puede llegar a una interpretación distinta de la obra: la habitación y las calles de Padua son el espacio del Juan social; el jardín es el espacio del "yo" interior de Juan. Él pasa de uno a otro espacio en su búsqueda de la experiencia original, erótica, de la unión con ese "otro" que es él mismo: el Amante. Este pasaje se hace gracias al balcón de su recamara, que funciona como una "ventana" hacia lo más profundo de la psicología del personaje. Este balcón no está del todo en la habitación pero tampoco está en el jardín; él constituye el espacio físicamente visible para el espectador entre el interior y el exterior. Funciona entonces como puente entre uno y otro espacio. Éste está cerrado, es Isabel quien lo abre. Este segundo personaje femenino, al igual que el Mensajero, no puede relacionarse con alguna figura de las cartas del Tarot. Al parecer es completamente prescindible, sino es porque permite que se desencadene la historia. A pesar de la opinión generalizada sobre este personaje secundario, se debe reflexionar sobre el papel que desempeña en La hija de Rappaccini; dado que se trata de una representación teatral, nada es gratuito.

Isabel es la casera de Juan, ella le da la habitación que yuxtapone los dos espacios de la obra por medio de su balcón; su papel, desde esta perspectiva, se torna fundamental: se convierte en la "llave" que posibilita el paso de Juan del exterior al interior. Sirve de estímulo para la transgresión entre espacios puesto que es ella quien "presenta" a Juan a Beatriz y le da las rosas que él obsequia a la joven. Isabel puede ser comparada con el personaje de la Patrona en la obra La serrure de Jean Tardieu. En la pieza del francés, la Patrona es la que tiene en su poder la llave de la puerta — de dimensiones sobrenaturales, lo cual indica que se pasa a otra realidad - que permitirá al Cliente satisfacer sus fantasías: "À gauche, en oblique, une porte d'aspect fúnebre: elle est de proportions inusitées, peinte en blanc sale, avec un encadrement noir [...] La Patronne est une volumineuse dame très mûre, aux cheveux décolorés, vêtue d'une robe prétentieuse aux couleurs criardes. Elle tient à la main un trousseau de clés" (1966: 46).

La comparación posible no es una coincidencia; Octavio Paz conocía bien la obra de Tardieu. La traducción de Oswald et Zénaïde ou Les Apartés y su puesta en escena para el mismo programa en que aparece La hija de Rappaccini así lo confirman. De hecho, La serrure es representada por primera vez en junio de 1955 en el Théâtre de 
la Huchette en París, tan sólo un año antes del segundo programa de "Poesía en Voz Alta”. No sería posible establecer una influencia; lo que sí podría decirse es que las imágenes son parecidas y que la función del balcón es equiparable a la de la puerta en la obra del dramático francés. Es el umbral que hay que cruzar para ahondarse en lo más profundo de "yo" interior, para conocer ese "otro" que se lleva dentro y que no surge sino en el viaje que se emprende por medio de la interiorización.

Sin duda, Paz, al recrear el personaje de Lisabetta, pensó en ir mucho más allá que Hawthorne. Su personaje a primera vista circunstancial adquiere en La hija de Rappaccini de Paz una dimensión fundamental. El juego sonoro de "Lisabetta" y "Beatriz" con sus aliteraciones en "b" y " $t$ " podrían llevarnos a una nueva interpretación en la que lo dicho por el Mensajero — respecto de la carta del Juglar ("pero ha oído el canto el canto nocturno de la Dama y ha despertado; guiado por ese canto, marcha sobre el abismo con los ojos cerrados, balanceándose sobre la cuerda floja") (1990: 17)— nos llevaría a pensar en que Juan ha sido invocado por la Dama... y ¿quién sería la Dama? ¿Beatriz o Isabel? Pero esto sería obligar a decir al texto algo que no ha dicho puesto que la mujer de avanzada edad no es Lisabetta sino Isabel. Y sin embargo, resulta difícil no pensar en que existe un paralelismo entre La hija de Rappaccini de Paz y Aura de Carlos Fuentes, como ya lo ha apuntado Lois Parkinson (1984) — sobre todo si se considera que Fuentes contribuyó en "Poesía en Voz Alta" escribiendo el comentario al segundo programa. Tampoco sería descabellado pensar que el personaje de Ixca en La región más transparente fuera su propia interpretación del Mensajero de La hija de Rappaccini. Así, a pesar de ser la única obra de teatro de Octavio Paz, La hija de Rappaccini reúne en unas cuantas páginas la compleja red de ideas que el escritor mexicano había externado en sus diferentes ensayos e inspira la producción de otros.

\section{Obras citadas}

BLASI, Alberto. 1979. “Artificio e intencionalidad de La hija de Rappaccini”. Cuadernos Hispanoamericanos, 342-345. Pp. 525-532.

Breton, André. 1985. Manifiestos del surrealismo. Trad. Andrés BosCH. Barcelona: Labor.

CATÁN, Daniel. 1991. "La música de La hija de Rappaccini: cartas no echadas a Octavio Paz”. Vuelta, 15.173. Pp. 28-31.

CHAVARri, Raúl. 1979. "Fantasías, mitos, símbolos y poéticas en el teatro de Octavio Paz". Cuadernos Hispanoamericanos, 342-345. Pp. 503-524.

DAUSTER, Frank. 1978. "La hija de Rappaccini: dos visiones de la fantasía". Revista Inter-americana de Bibliografía, 28. 2. Pp. 157-163.

GIRARD, René. 1983. La violencia y lo sagrado. Trad. Joaquín JoRDÁ. Barcelona: Anagrama.

GONZÁLEZ Pelayo, Irma. 1991. "Soledad y comunión, ejes del pensamiento poético en La hija de Rappaccini de Paz". Literatura Mexicana, 2.1. Pp. 121-134. 
HAWTHORNE, Nathaniel. 1982. "Rappaccini's Daughter”. Tales and sketches. Nueva York: Library of America. Pp. 975-1005.

Magaña EsQuivel, Antonio, comp. 1970. Teatro mexicano del siglo XX. México: FCE.

PARKINSON ZAMORA, Lois. 1984. “A garden inclosed: “Fuentes's Aura, Hawthorne's and Paz's Rappaccini's Daughter, and Uyeda's Ugetsu Monogatari”. Revista Canadiense de Estudios Hispánicos, 8.3. Pp. 321-334.

PAZ, Octavio. 1997. Obras completas XI: Obra poética I (1935-1970). México: FCE. . 1994. "Estrella de tres puntas: el surrealismo". Obras completas II, Excursiones / Incursiones. Dominio extranjero. México: Circulo de Lectores / FCE. Pp. 203-214. 1990. La hija de Rappaccini. México: Era. . 1989. Los hijos del limo. Barcelona: Seix Barral. . 1971. Traducción: literatura y literalidad. Barcelona: Tusquets. . 1956. La hija de Rappaccini. Revista Mexicana de Literatura, 2.7. Pp. 3-26.

TARDIEU, Jean. 1966. La serrure. In Théâtre de chambre. París: Gallimard.

Unger, Roni. 1981. Poesía en Voz Alta in the theater of Mexico. Columbia / Londres: University of Missouri Press.

Verani, Hugo. 1996. Bibliografía crítica de Octavio Paz (1931-1996). México: El Colegio Nacional.

WiLson, Jason. 1986. Octavio Paz. Londres: Twayne Publishers. 